\title{
Critical self-reflection as disruption: A Black feminist self-study
}

Benikia Kressler ${ }^{1 *}$

${ }^{1}$ California State University, Fullerton

*Corresponding Author: bkressler@fullerton.edu

Received : 2019-NOV-08

Accepted : 2020-MAY-28

DOI: $10.46303 /$ jcve.03.01.2

How to cite this paper: Kressler, B. (2020). Critical Self-Reflection as Disruption: A Black Feminist Self-Study. Journal of Culture and Values in Education, 3(1), 21-38. https://doi.org/10.46303/jcve.03.01.2

\begin{abstract}
As the preschool through 12th grade student population grows more diverse, the teaching population steadfastly continues to be predominantly white, middle-class women (National Center for Education Statistics, 2016). Critical teacher educators understand the importance of preparing pre-service teachers to become culturally responsive and sustaining (CR/S) practitioners by engaging in culturally relevant education (CRE). Critical teacher educators, particularly those of color from historically marginalized groups, can be important advocates in the struggle to strengthen the teaching candidate pool of $\mathrm{CR} / \mathrm{S}$ practitioners. Building a cadre of teachers, who are poised to decolonize minds and spaces, sustains the work of many teacher educators of color. However, the acts of teaching and learning in most institutions of education are inundated with oppressive norms such as white privilege, xenophobia, and anti-Blackness. It is this reality in which I, a Black female junior teacher educator, attempt to disrupt normative teaching practices within a special education course. This self-study examined insight derived from a focus group as well as from my self-reflections conducted over the course of two semesters. Using a qualitative methodological approach, the findings indicated tensions between my vulnerable position of being a junior faculty member and my desire to dismantle normative deficit practices through critical self-reflection.

Keywords: self-study, junior faculty, preservice teachers, culturally responsive education, teacher education
\end{abstract}




\section{Introduction}

As a first-generation college graduate and someone who earned a $\mathrm{PhD}$, I have learned from many teachers with seemingly good intentions. They taught me how to read, write and access the white-dominated world around me. They also taught me that the colloquial nature of my vernacular, often used in the African American community, was inappropriate. I further learned from teachers that growing up in a single parent household in a low-income neighborhood would be a detriment to my life. I was told that my best chances of success consisted of leaving (and forgetting) where I came from to pursue a higher education. In 'educating' me, they were both passively and unintentionally as well as explicitly and intentionally, teaching me to access the white-dominated world around me while simultaneously teaching me that my communities and culture could not be valued.

Like the majority of those in the teaching force today, my teachers were mostly white, middle class women who were educating an increasingly diverse student population (National Center for Education Statistics, NCES, 2016). Unfortunately, they lacked both the training and characteristics to engage in teaching in a culturally sensitive and competent manner that $\mathrm{I}$, as a student, and others like me needed. We needed teachers skilled in cultural competence so we could be successful students and reduce our chances of becoming alienated within our communities. The needs of both culturally and linguistically diverse (CLD) students as well as students with (dis)abilities, independently and as they intersect, demands greater understanding. This understanding involves all teachers having a level of expertise that not only comes from experience but also explicit training. It requires a concerted effort and commitment to reduce long standing trends of the overrepresentation of CLD youth in special education (Artiles et al., 2010; Harry \& Klingner, 2006; Klingner et al., 2005). It also requires reducing school dropout rates, particularly for students labeled with a (dis)ability, which are disproportionately higher for students of color (NCES, 2012). Therefore, it is imperative that both general and special education teachers are equipped with the disposition, knowledge, and ability to support the needs of CLD students with and without (dis)abilities to provide educational opportunities beyond "survival" and to truly thrive (Love, 2019). Importantly, it is vital to understand that the aforementioned issues are not coincidental, but are due to systemic white supremacy which affects students and families with identities where race/ethnicity, class, and (dis)ability intersect.

Ultimately, there is an urgent need for teacher education programs and instructors/professors in higher education teacher preparation programs (hereinafter referred to as "teacher educators") to equip teachers with the culturally relevant and social justice knowledge needed to support vulnerable students (Aronson \& Laughter, 2016). Teacher educators need ongoing training in the forms of self-study groups, teacher inquiry groups, and/or critical professional development (Dover et al., 2019; Grierson, 2010; Kohli et al., 2015; Martinez et al., 2016). Despite these training needs, under the guise of "diversity and inclusion" efforts, teacher educators are expected to prepare teacher candidates to teach $\mathrm{K}-12$ students in 
just and equitable ways. As a Black female junior teacher educator of special education teacher candidates (SETCS), I use culturally relevant education (CRE) to meet this call. CRE is a combination of asset pedagogies introduced and popularized by Geneva Gay (2010) and Gloria Ladson-Billings (1995, 2014). According to Aronson and Laughter (2016), CRE recognizes both the competencies and practices of teaching stressed by Gay (2010) as well as the attitudes and dispositions of pedagogy outlined by Ladson-Billings (2014). The power of CRE lies in its social justice foundation and its disruption of neoliberal education reforms which exalts free markets, competition, and individualism (Aronson \& Laughter, 2016; Sleeter, 2012). Specifically, I instruct SETC to engage in critical self-reflection, an important disruptive practice and an essential foundational factor to prepare teacher candidates to teach toward equity and justice (Aronson \& Laughter, 2016; Howard, 2003). Critical self-reflection disrupts the norm in that it is the "honest self-reflection and critique of [one's] own thoughts and behaviors. [It] requires one to seek deeper levels of self-knowledge and to acknowledge how one's own worldview can shape students' conceptions of self" (Howard, 2003, p. 198).

My identity as a Black Female, and my lived experiences therein, makes the use of CRE in special education settings particularly compelling. I am often inspired to use CRE to disrupt the colorblind and ahistorical nature of a typical special education curriculum. I have learned that teacher candidates of color often have deficit views of CLD students with (dis)abilities and engage in colorblind ideologies which are supported by courses, activities, and rhetoric within teacher education programs that value the medical model of the curriculum (Taie et al., 2017). This medical model is problem/deficit based and perpetuates inequalities at the intersection of race, gender, class and ability (Kulkarni, 2018). Colorblind beliefs in special education can maintain white supremacy by creating confusion in both research and practice about the issue of disproportionality in special education (Artiles et al., 2010; Blanchett, 2006). These deficit views and colorblind ideologies are maintained in part because teacher education program lacks clear social justice and anti-racist focused curriculum (Pugach et al., 2020).

I am led to teach my SETCs in a clear, anti-racist, and liberating manner, but the legacy of colonization and white privilege in both my kindergarten through 12th (K-12) grade schooling and institutions of higher education affects my efforts. In teaching assessment in special education courses, I know I only infuse CRE, rather than truly transform the existing curriculum with social justice and equity-focused content. Therefore, this effort only minimally contributes to the overall transformation of the minds and practices of SETCs towards advocacy for their future CLD students with and without (dis)abilities (Pugach et al., 2020). While grappling with this reality, I am also aware that I have never been formally trained regarding how to teach CRE to teacher candidates. My lack of formalized training is an issue shared with most teacher educators (Goodwin et al., 2014). There is a general assumption that teacher educators who have taught in preschool through 12th grade (PK-12) settings are inherently capable of teaching equity pedagogy to teacher candidates. The reality is that PK-12 teacher experience is useful but not enough to be experts in CRE (McAnulty \& Cuenca, 2014). 
I am led to teach for liberation and equity for all students and, as such, I generally welcome the call to do this work. However, in the world of special education (with its colorblind and deficit orientation), the lack of a clear social justice stance in the teacher program curriculum is normative. Consequently, when SETCs encounter CRE practices in special education courses, it is a disruption of what they typically experience in the program. As a junior teacher educator in a position eligible for tenure and promotion (i.e., "on the tenure track"), I am aware of my tenuous position and have questioned whether to engage in disruptive practices like CRE. During this time in my career women of color are especially more likely to be denied tenure than white males (June, 2012; Wilson, 2016). Bringing attention to myself and my practices in a way that may bring pushback from students about my teaching methods may jeopardize my career trajectory.

This self-study examined the benefits and challenges of engaging in CRE, specifically critical self-reflection, as a junior faculty member on tenure track. I used focus group interviews from SETCS over the course of two semesters to understand their perceptions of my use of critical self-reflection in a special education assessment course. I also used my personal reflections to understand the relationship of doing this work and the context of being a Black, female, junior faculty member. The following research questions guided my study: What are the benefits and challenges of engaging in disruptive practices within my special education course? and, To what extent does engaging in critical self-reflection result in challenges that are detrimental enough to my budding career to deem them unwise to implement?

\section{Conceptual Framework: Black Feminist Theory}

From standards of beauty, access to health care and positions of educational, political, and economic power, Black women are consistently marginalized and placed in inferior positions within society. This self-study utilized Black feminist theory as a nuanced framework for understanding how my efforts to disrupt hegemonic teaching practices collided with external and internal resistance within a white dominated teacher education program. Black feminist theory offers an analytic frame to understand this shared social world that is historically grounded in a "legacy of racism, sexism, class exploitation and heterosexism that assign categories of superiority and inferiority" (Gist, 2016, pp. 245-246). In the context of academia, Black women are marginalized in total number; they are in the lowest percentages of tenured faculty at $3 \%$ whereas white men make up the highest at $45 \%$ (NCES, 2020). Being Black and female also equates to lower wages when compared to white males (Li \& Koedel, 2017; McChesney, 2018). In addition, Black women in higher education experience microaggressions, isolation, and increased stress linked to race and gender (Kelly \& WinkleWagner, 2017). Indeed, navigating higher education as a Black female can be frustrating and depleting.

Black feminism provides context and analysis of the ways in which Black women are both marginalized by and resistant to these inferior positions. By honoring the lived experience 
of discrimination, exploitation, and oppression of Black women as knowledge sources, Black feminist theory provides a liberating toolset to contextualize and free minoritized women of color (Gist, 2016). This toolset allows Black women to embrace their lived experiences in typically white spaces, like institutions of higher education. The framework also offers the reimagining of these experiences as an advantage as it provides a means of creating a counterhegemony through practices of shared collective responsibility (Hooks, 1984; Phendla, 2008). Collins' (1989) states,

The long-term and widely shared resistance among African American women can only have been sustained by an enduring and shared standpoint among Black women about the meaning of oppression and the actions that Black women can and should take to resist it (p. 746).

These ideologies encapsulate why I and other Black women are led to engage in work using methods that advance activism and social justice while concurrently experiencing marginalization.

\section{Method}

\section{Research Design}

This is a qualitative self-study which utilized student focus group interviews triangulated with my personal reflective journals, to explore the benefits and challenges of including critical self-reflection in a special education course. Self-study is a method which centers on the self and her personal experiences (LaBoskey, 2004). This self-study is interpretive (Crotty, 1998) in that it is used to understand my own experiences. This work is not linear, but recursive, meaning it requires going back to the beginning several times in order to make sense of the data. Consequently, data analyses and interpretations are intertwined (LaBoskey, 2004). The recursive nature of the study allowed me to use the data to situate it in the disruption which is derived from engaging SETC during critical self-reflection in an assessment course as a junior faculty member.

I began the disruptive practice of critical self-reflection when I was assigned to teach the only assessment course in our special education PK-12 program during the Fall of 2015. I was given a multitude of supportive instructional materials to help me get started; however, previous course content was devoid of discussion around issues of teacher bias, bias in standardized testing, or issues of disproportionality in special education placement which are all critical to CRE. In sum, the course lacked a clear equity and justice focus. Although there is no requirement to add these particular elements in the course, not discussing these issues upholds historically inequitable systems of anti-Blackness and white supremacy. I could not teach this course without addressing these issues of inequity. Therefore, I decided to ground the course in CRE pedagogy. When I first included curricular materials regarding racial discrimination, to decolonize the assessment curriculum, I noticed SETCs were confused about how to engage in assessment in a culturally responsive way. They did not understand how to 
engage because they did not comprehend that their decision making was a key driver of the outcomes of their students. As part of the course design, I decided they needed to reflect on their personal experiences, including how their cultural background could affect them as future teachers, and how these are important components which contribute to student outcomes. Consequently, when I gathered data about my instruction of CRE practices, I grounded the data in critical self-reflections of SETCs.

\section{Participants and Data Collection}

This self-study focused both on an examination of students' perceptions of my teaching and my use of critical self-reflection. After receiving approval from the Institutional Review Board (IRB) at my University, I recruited students from my special education assessment course to participate. Consent was obtained to use course assignments and critical reflections for the study. Data from a total of four focus group interviews were collected over two semesters. Each focus group consisted of five students, for a total sample of 20 participants. These students also completed a survey which identified 17 of the 20 participants as female. The race and ethnicity of the focus group participants were not gathered in order to maintain confidentiality. All participants were post baccalaureate special education credential candidates.

The focus group interview questions included items about my teaching and modelling of CRE. The questions also included an item about candidate perceptions of self-reflection as a tool to enact CRE with CLD learners. Participants answered a total of five open ended questions at the end of the semester. They gathered in groups of five to seven to answer the questions aloud. Their responses were audio recorded and later transcribed. To maximize student participation and minimize undue pressure from myself, I was not present during sessions and, instead, a group leader facilitated the audio recording process. The focus group interviews each took 35 minutes to complete. As additional data collection, I also periodically wrote reflective journal entries regarding my own teaching and thinking processes. Reflective journal entries were used to document the joys and tensions of teaching CRE, specifically critical self-reflective practices, in a special education assessment course. I produced a total of 10 reflective entries during the Spring 2018 and Fall 2018 semesters.

\section{Data Analysis}

The focus group interviews were transcribed and analyzed using In Vivo coding and Concept Coding (Saldaña, 2016). These coding processes may also be used in grounded theory methodological approaches (Charmaz, 2006) and are useful to understanding the overall meaning of student data and considering the context of my own reflective journal entries. I analyzed the focus group interviews in large segments in order to understand the broader meaning of the data. In some segments of the data, the participants' own words provided the unit of analysis necessary to understand a specific section (Saldaña, 2016). For those sections, I used In Vivo codes. For other segments of interview data, I used Concept Coding. Concept coding is using a "word or phase to symbolically represent a suggested meaning that's broader 
than a single item or action" (Saldaña, 2016, p, 292). This allowed me to assign "meso" or "macro" levels of meaning to qualitative data (Saldaña, 2016, p. 292). Thus a paragraph of focus group data was given meaning using a phrase that captured the larger meaning of the segment. In total, I employed 4 In Vivo codes and 14 Concept codes. I then used the constant comparison method to develop categories (Corbin \& Strauss, 2008). Developing categories allowed me to consolidate the meaning of the Concept and In Vivo codes into a smaller number and more abstract codes. This process yielded nine categories. In the final phase of this analysis, again using the constant comparison method, I derived three emergent themes. Themes are a collection of more implied processes found within the data.

I used my personal self-reflections as data to triangulate the focus group interview analysis as well as contextualize the environment in which I was teaching. In total, there were 10 journal entries ranging in length from a paragraph to a couple of pages. These narratives were not systematically coded. Instead, they were used as a backdrop of the success and tensions I felt while engaging in this work. I cannot claim that these reflections are unbiased as my aim was not trustworthiness of my thoughts but, rather, simply provide truthful feelings as I perceived it during this process.

\section{Positionality}

My positionality toward this topic of critical reflection as disruptive praxis is rooted in my identity, lived experiences, and epistemological cultural stance. I identify as a Black cisgendered able-bodied female and first generation college graduate. My personal experiences included growing up in the projects with a single mother, and having to work early in life to support my family. I learned that to be successful and accepted (by teachers/authority figures) I had to be silent and follow rules. These experiences inform the struggle I encounter as a junior faculty member teaching in a white dominated space. It also informs my use of Black feminist theory as an analytic tool to understand my experiences living, (un)learning and internalizing marginalization while concurrently being lead to resist and disrupt oppressive practices in the current leadership position I hold as a tenure-track faculty member.

As a junior faculty member new to teaching preservice teachers and wanting to improve my own teaching for social justice, I developed this research project to examine my own teaching and understanding of some of the tensions I felt while implementing reflective practices within my course. I also wanted to have students' voices as part of this reflective process, so the participants in this study are former students. I did not collect demographic information on these candidates for confidentiality purposes; however, I teach in a Hispanic Serving Institution and rarely have Black teacher candidates. Thus, most of the participants do not share my racial identity. Like me, most of the teacher candidates were female and had some experience working with students with disabilities (them as paraprofessionals or counselors, me as a high school teacher). Because of these shared experiences, I was able to connect with them and provide a safe, and at times brave, space for candidates to open up about their background and personal biases. Although I had these shared experiences with 
some of my candidates, I worked to separate my assumptions and biases from their focus group data by de-identifying the data two months before reading and analyzing it. I wanted to present the data they provided as close to their own words as possible to ensure their perceptions were clear. I also wanted my thoughts and perceptions to be represented to underscore my tensions during the time of the study.

\section{Findings}

Candidates in the focus groups shared their perceptions of the use of CRE in my teaching, specifically self-reflective practices, within a special education course focused on the assessment of students with (dis)abilities. The focus group data yielded three themes: importance of self-reflections, bias and cultural awareness, and struggling to push through. These themes along with some contextual passages from my own self-reflections are discussed below.

\section{Theme 1: Importance of Self-Reflection}

When the SETCs initially learned that they would be engaging in self-reflective practices within the special education course they were confused. One SETC stated, "This was something I was not expecting from this course. Since this course was labeled as an assessment class, that's what I thought the whole focus would be on." Another candidate shared this sentiment by stating, "My overall impression of this course's focus on reflective practices to engage in culturally responsive assessment was at first very confusing. I didn't see how focusing on culture had anything to do with special education assessments." These statements were consistent across the focus group data, underscoring the disconnect between CRE and important elements of special education such as assessment.

Although they were confused in the beginning of the course, the focus group data indicated that SETCS believed self-reflection was an important tool in the process of getting to know their CLD students in order to make appropriate assessment decisions. One SETC commented:

[Because of self-reflection], I started thinking about whether or not [the assessment] was appropriate for the student. I think moving forward, I will be more aware of the type of assessments I will give and the importance of getting to know my own students.

This course really made me reflect on myself and my own biases and views.

Other SETCs had similar comments such as, "The reflections really helped me think about my own views and the importance of reflecting on my relationships with my students." The SETCS saw the practice of self-reflection as a way to think about and connect with their students in order to make better educational decisions for diverse students.

Overall, candidates stated that engaging in self-reflective practices was important and they enjoyed that they were exposed to the process in class. One SETC stated, ...quite honestly, [reflective practice] is something I would have never thought about 
prior to this course. I feel that it is important to reflect on why we feel certain ways about certain students because if we reflect on why we feel the way we do, only then can we adequately teach these students. This course really opened my eyes to begin to understand why it is important to reflect prior to teaching.

The focus group data indicated that engaging in the self-reflection process in class was a meaningful endeavor for SETCs because it provided the opportunity to make the connection between their personal selves, its impact on their teaching decisions, and how those outcomes affect their students.

While SETC data indicated an appreciation of the self-reflection process, my own selfreflective journals noted tensions around my need to slow down and push my SETCs to reflect and act, and the lack of time to do this work and other requirements of junior faculty on tenure track. One entry from Fall 2018 highlights this sentiment,

Although having students engage in this [self-reflective activity], using groups was much more effective than the standard lecture. I am so aware that they are not being challenged to change or DO anything in practice. I am still struggling with pushing students to do more in practice. But between writing manuscripts, research projects, service requirements, mentoring master's students etc..., finding the time to get students to move beyond self-reflection feels impossible.

This passage underscored my understanding that SETCs should be challenged to go beyond the classroom exercise of self-reflection and my limitations in pushing them, in part, due to other responsibilities as a junior tenure track faculty member.

Interestingly, the lack of time that I felt was similar to how some SETCs felt about selfreflective practices. Although they believed that self-reflection was necessary, the realities of teaching did not permit them the time to do so. One candidate from Spring 2018 stated, Self-reflection, I think is one of the most important parts of growing and being a well-rounded educator and human, you know, being a teacher I think that we don't have enough time and energy to just stop and kind of self-reflect and take into account what has worked and what hasn't worked and how we view certain students and how we treat certain students in certain situations.

This candidate was an intern meaning that she was actively teaching (as were the majority of SETCs during Spring 2018). The sentiment of this quote not only captures that of many others in this study, but also my own. Despite the importance of self-reflective practices there were also clear tensions between knowing it is important and actually doing it in practice.

\section{Theme 2: Bias and Cultural Awareness}

In addition to seeing the importance of self-reflection, candidates also discussed how the practice helped them develop an awareness of their culture and their own personal biases. These ideas aligned with Villegas and Lucas' (2002) definition of sociocultural consciousness which asserted that the way people (i.e., teacher candidates) think about others is influenced by their culture. One candidate from the Spring 2018 semester, for example, articulated how 
the course supported her development of sociocultural consciousness by discussing her understanding of the importance of identifying personal biases. She explained how important it is to be mindful of how her culture impacts her decision making for diverse students who receive special education services:

I liked that it really taught me something about having an awareness of my own thoughts and my own opinions and my own culture. I always thought that I didn't have any culture! [But] my family has its own culture and there's so much that directly impacts who I am and so if it's true for me it's true for everybody. So to be able to look at a person and think about how their experiences shape not just their language, background...but if they're from or their parents are from another country or another state or something, there's so much that goes into it. So, I appreciated the ability to have a much higher awareness of these things going in so that I can have an open mind when I am assessing or writing IEP goals or any of that.

Engaging in critical self-reflection proved to be a powerful way for candidates to understand the connection between CRE and the assessment process to support equitable outcomes for CLD youth who are placed in special education classes. Candidates made connections and questioned their own thoughts and feelings. For example, one candidate from the Spring 2018 semester stated, "I liked that in this class she addressed your own personal biases [through critical self-reflection] because I think it's something that we don't stop often enough to be like, 'What is our issue here?'" Similarly, another SETC from the Fall 2018 semester commented, "I now know that it is extremely important to be reflective prior to engaging in assessments so that we can eliminate the biases we may feel with some students." Focusing on critical self-reflection encouraged candidates to have an open mind about the purpose and nature of assessment and decision making for special education services. They made some meaningful connections and strengthened their understanding about their own cultures.

My self-reflections indicated the intentionality of explicating culture and bias in the course. I wrote about the activities and lectures I provided which specifically centered on reflecting on background, culture, and bias. I expressed my desire for SETCs to be exposed to critical issues in special education even as I was beginning to feel that there could be some pushback because of preconceived notions of what an assessment course should entail. I wrote, "I am feeling unsure and insecure in my decision to contextualize this course in CRE before I have tenure." This tension between having students engage in the critical work of selfreflection in my course and gaining tenure was an on-going dynamic throughout my reflections.

\section{Theme 3: Struggling to Push Through}

Although grounding a very practical and mostly deficit orientated course in CRE with a focus on critical self-reflection had some positive outcomes, my reflective journaling indicated that I was troubled by my internal struggle to push students towards action in practice, but not pushing so much that I hurt my chance for tenure. My reflections during Spring 2018 showed 
my awareness of my lack of effort to challenge SETCs further. In one note from my journal entry, I wrote:

Students did a great job discussing [article on CRE and Response to Intervention] today.... want them to understand and reflect on the importance of engaging in assessment practices using CRE. Students seem to enjoy having discussions around this topic. Although having students engage in this, using groups was much more effective than the standard lecture. I am so aware that they are not being challenged to change or DO anything in practice. I am still struggling with pushing students to do more in practice.

Candidates were also becoming more aware of their own culture and biases, but I did not require them to engage in/report on actions to ensure equity. Not enforcing action was an uncomfortable but conscious decision. In many ways, my reflections continued to highlight my worry about gaining tenure. From my comments about the "colorblind culture" of the department, the courses shared with me that were ahistorical and completely devoid of critical pedagogy, to various conversations on the need to improve student evaluations by reducing talk on CRE, it all seemed to heighten my worry about the viability of gaining tenure.

My reflections during Spring of 2018 underscored my worries concerning whether I pushed SETCs hard enough to make a difference in the lives of their PK-12 students while simultaneously worrying about receiving poor teaching evaluations which could negatively affect my livelihood. This hyper worry led me to "play it safe" that semester by not pushing SETCs to engage in reflective prompts that were too "uncomfortable". Despite this attempt, three of the five focus groups that semester still had a number of statements about not learning enough about assessments and learning too much on CRE practices. One SETC stated:

I feel like I learned quite a bit about culturally responsive/competent assessments because of this class. Specifically about the overpopulation of certain people in special education due to testing bias and biases, but my overall knowledge of the assessment themselves in special education did not improve quite as much as I hoped it would, except with a few of the tests. But I would have liked to know about more tests that I could give to students, especially for students with [moderate or] severe disabilities.

This SETC's statement was an exemplar of what other candidates felt that semester; the course focused too much on CRE and not enough on assessment. The comment also brought to reality my worry about student opinions of my teaching.

During Fall 2018, my reflections continued to highlight some worry, but not to the extent as it did during Spring 2018. My self-reflections focused more on pedagogy and getting to know my students. I also encouraged students to engage in more meaningful self-reflective practices by providing a "Brave Space" in the classroom. Candidates in Fall 2018 noticed my efforts to encourage braver discussions and reflections in class, even if they were unpopular.

Dr. Kressler modeled [self-reflective] practices in this course. There were times where we had class discussions and some people would say things that seemed biased and very close-minded. Dr. Kressler never responded in a negative manner. She would ask 
questions to figure out the student's perspective and at times seemed to help the student clarify their [thoughts]. Many students felt comfortable enough in the class to admit their biased perspectives and views.

Overall there was a clear difference between candidates' perceptions of the course and my teaching it within a CRE framework. Although I taught the same content in both classes, the perceptions of what was learned was very different. Instead of seeing an integrated CRE and assessment course, candidates in Spring 2018 saw a disjointed, CRE-heavy class. My reflections were also different across semesters as I focused more on my pedagogy and getting to know the candidates during Fall 2018. I believe this created a more positive learning environment, improving my pedagogy, and possibly reducing my focus on gaining tenure.

\section{Discussion}

The purpose of this self-study was to examine the enacting of CRE through the use of critical self-reflection within an assessment in a special education course. Teacher candidate focus group interviews and my own reflective journal entries uncovered the realities of this work during the Spring 2018 and Fall 2018 semesters. Data revealed three emergent themes which indicated that as a junior faculty member, engaging in disruptive practices like critical self-reflection was both beneficial and challenging. It was positive that most SETCs grew from the redesign of the course and gained cultural awareness through and appreciation of critical self-reflection. Other studies have demonstrated that teacher candidates became more aware of the importance of CRE practices through explicit instruction regarding the concept (Acquah \& Commins, 2017; Iwai, 2013) and that reflection was an important aspect of good teaching (Addleman et al., 2014). Both cultural awareness and critical reflection are necessary components to become culturally competent (Howard, 2003; Ladson-Billings, 2014). However, I was challenged to negotiate my drive to disrupt the curriculum in the context of my marginalized identity as a Black female and my tenuous junior faculty position.

Other studies have addressed the tensions found in teaching for equity as a junior faculty member (Kelly-Jackson, 2015; Mitchem et al., 2020). The main issue is having the passion and desire to teach what you believe while grappling with the realities of one's junior status in white-dominated spaces (Baxely, 2012). When summing up her feelings about student reactions towards including social justice issues within a secondary science methods course, Kelly-Jackson (2015) wrote,

As I reflect on the semester, I am disappointed in myself for giving up on these students and on myself. It was definitely not my intention, but as the complaints began to spread to other faculty and students began to resist my approach, my concern shifted more towards my reputation as an educator in a tenure-track position. I began to wonder how my course evaluations would look and how they would impact me in the tenure and promotion process (p.177). 
I also wondered about how my student evaluations of teaching (SETs) would be judged after pushing students to go beyond the standard curriculum. The most troubling experience as a junior faculty member is the feeling that you may lose your job if teaching is primarily evaluated using SETs. Using SETs to judge teacher effectiveness has revealed that teaching for equity or justice is not highly valued. There are decades' worth of research indicating the problem of using SETs to evaluate teaching effectiveness (Braga et al., 2014), such as bias against women (MacNell et al., 2015) and against people of color (Reid, 2010; Smith \& Hawkins, 2011) yet, they are still used heavily to judge teaching performance. My personal reflections were heavily influenced by my worry regarding how students would perceive my teaching and rate me on SETs. This limited how far I pushed my students to engage in the work. As untenured faculty, it is difficult to risk "rocking the boat" this early in my career. Phendla (2008) underscores this sentiment with the following statement: "Holding leadership roles as a Black woman can be likened to holding the sharp edges of knives. As a result, women have to learn strategies on how to hold these knives without being cut" (p. 23-24). Sometimes this resistance means remaining silent so that they can choose to disrupt and resist in the future.

Even with the doubts and fears, I still taught my candidates using an equity lens by engaging in a disruptive practice. As a Black female from a low-income socioeconomic background, I am led to advocate for marginalized and vulnerable groups because I would not be a junior faculty member if it were not for others pushing boundaries on my behalf. It is also important for me to maintain my position so I can continue to represent people of color and women who are underrepresented in mostly white spaces.

\section{Implications}

One implication of this study is the development of professional learning communities. Junior faculty who advocate for justice and culturally responsive practices, particularly in nondiversity specific courses, need support when doing this complex work. Although limited, there is a growing body of research focused on the support of teacher educators who teach for equity and justice (Dover et al., 2019; Picower \& Kohli, 2017). This research highlights the daily tensions faced by faculty who teach for equity and justice but it also underscores how professional community and critical professional development can reduce the pressures of the job. These spaces also invite discussions regarding ways to advocate for oneself. Dover et al. (2019) found that critical professional development provided a community of support which also functioned as a sounding board for ideas to fight for one's career and to find one's voice in an overwhelmingly white cultured space.

The findings from this study also suggest that having only one or two equity-focused courses within a teacher education program is problematic. At best, individual critical teacher educators have attempted to infuse the existing curriculum with social justice and equityfocused content. However, these efforts do little overall to transform the minds and practices of teacher candidates towards advocacy for their future CLD students with various abilities (Pugach et al., 2020). This issue hinders the transformative struggle to engage in the work 
within teacher education programs. It also highlights the fact that some teacher education programs' reluctance to decenter whiteness and decolonize itself depletes and devalues the efforts of faculty of color. This work cannot be accomplished in a silo as the entire teacher education program should have clear and explicit social justice frameworks. The program should ensure that all courses, including methods courses, are grounded in CRE and social justice practices.

Additionally, junior faculty of color who perform equity work need support from senior faculty who serve on department personnel committees (DPCs). When new faculty join a department, especially if potentially perceived to be a "diversity hire," faculty learning communities are important to have ready in order to support them in meaningful ways. This includes the way SETs are evaluated and eventually judged by DPCs. If it is clear that students' negative comments mainly target the addition of an equity or critical lens within a course, DPCs should not use those comments to judge faculty members' yearly teaching portfolios.

\section{Conclusion}

Teaching using critical self-reflection as a junior faculty member is a disruptive practice in white dominated spaces. As a Black female, I wrestle with the divide between teaching candidates to support vulnerable CLD students using CRE and maintaining my career. Unfortunately, it is frustrating to have to balance between the divide. However, I have hope that with the addition of professional learning communities and the recognition of the biases of SETs against women and people of color, efforts can still be productive. In the meantime, it is important for junior scholars to continue to teach for social justice, not only for teacher candidates and their future PK-12 students, but also for teacher educators. We must remember that if we fight for change and for the rights of marginalized groups, there will be resistance. Junior faculty of color are important players in the fight for justice at all levels of the academy. Junior faculty must be prepared to fight for themselves, their work, and their livelihood because the work matters, and so do they. The future of our teaching force and their students are worth the challenges this work brings. 


\section{References}

Acquah, E. O., \& Commins, N. L. (2017). Methods that matter in addressing cultural diversity with teacher candidates. Teaching in Higher Education, 22(5), 501-518. https://doi.org/10.1080/13562517.2016.1273217

Addleman, R. A., Brazo, C. J., Dixon, K., Cevallos, T., \& Wortman, S. (2014). Teacher candidates' perceptions of debriefing circles to facilitate self-reflection during a cultural immersion experience. New Educator, 10(2), 112-128. https://doi-org.libproxy.fullerton.edu/10.1080/1547688X.2014.898485

Alexander, M. (2010). The new Jim Crow: Mass incarceration in the age of colorblindness. The New Press.

Aronson, B., \& Laughter, J. (2016). The theory and practice of culturally relevant education: A synthesis of research across content areas. Review of Educational Research, 86(1), $163-$ 206. https://doi.org/10.3102/0034654315582066

Artiles, A. J., Kozleski, E. B., Trent, S. C., Osher, D., \& Ortiz, A. (2010). Justifying and explaining disproportionality, 1968-2008: A critique of underlying views of culture. Exceptional Children, 76(3), 279-299. https://doi.org/10.1177/001440291007600303

Baxely, T. P. (2012). Navigating as an African American female scholar: Catalysts and barriers in predominantly white academia. International Journal of Critical Pedagogy, 4(1), 47-64. http://libjournal.uncg.edu/ijcp/article/view/193

Braga, M., Paccagnella, M., \& Pellizzari, M. (2014). Evaluating students' evaluations of professors. Economics of Education Review, 41, 71-88. https://doiorg/10.1016/j.econedurev.2014.04.002

Charmaz, K. (2006). Constructing grounded theory: A practical guide through qualitative analysis. Sage Publications.

Corbin, J., \& Strauss, A. (2008). Basics of qualitative research (3rd ed.). Sage Publications.

Crotty, M. (1998). The foundations of social research: Meaning and perspectives in the research process. Sage Publications.

Dover, A. G., Kressler, B., \& Lozano, M. (2019). "Learning our way through": Critical professional development for social justice in teacher education. The New Educator, 16(1) https://doi.org/10.1080/1547688X.2019.1671566

Gay, G. (2010). Culturally responsive teaching ( $2^{\text {nd }}$ ed.): Multicultural education series. Teachers College Press.

Gist, C. (2016). A black feminist interpretation: Reading life, pedagogy, and Emilie. Meridians, 15(1), 245-268. https://doi.org/10.2979/meridians.15.1.13

Goodwin, A. L., Smith, L., Souto-Manning, M., Cheruvu, R., Tan, M. Y., Reed, R., \& Taveras, L. (2014). What should teacher educators know and be able to do? Perspectives from practicing teacher educators. Journal of Teacher Education, 65(4), 284-302. https://doi.org/10.1177/0022487114535266 
Grierson, A. L. (2010). Changing conceptions of effective teacher education: The journey of a novice teacher educator. Studying Teacher Education: Journal of Self-Study of Teacher Education Practices, 6(1), 3-15. https://doi.org/10.1080/17425961003668898

Harry, B., \& Klingner, J. (2006). Why are so many minority students in special education? Teachers College Press.

Howard, T. C. (2003). Culturally relevant pedagogy: Ingredients for critical teacher reflection. Theory into Practice, 42(3), 195-202. https://doi.org/10.1207/s15430421tip4203 5

hooks, B. (1984). Feminist theory: From margins to center. South End Press.

Iwai, Y. (2013). Multicultural children's literature and teacher candidates' awareness and attitudes toward cultural diversity. International Electronic Journal of Elementary Education, 5(2), 185-198. https://eric.ed.gov/?id=EJ1070461

June, A. (2012, February 25). Tenure decisions at southern cal strongly favor white men, data in a rejected candidate's complaint suggest. The Chronicle of Higher Education. https://www.chronicle.com/article/Tenure-Decisions-at-Southern/135754

Kelly-Jackson, C. (2015). Teaching for social justice and equity: The journey of a teacher educator. The New Educator, 11(3), 167-185. https://doi.org/10.1080/1547688X.2014.966400

Klingner, J. K., Artiles, A. J., Kozleski, E., Harry, B., Zion, S., Tate, W., Durán, G. Z, \& Riley, D. (2005). Addressing the disproportionate representation of culturally and linguistically diverse students in special education through culturally responsive educational systems. Education Policy Analysis Archives, 13(38), 1-40. https://doi.org/10.14507/epaa.v13n38.2005

Kohli, R., Picower, B., Martinez, A., \& Ortiz, N. (2015). Critical professional development: Centering the social justice needs of teachers. International Journal of Critical Pedagogy, 6(2), 7-24. http://libjournal.uncg.edu/ijcp/article/view/1057

Kulkarni, S. S. (2018). Towards a critical disability studies model of teacher education. In K. Ellis, R. Garland-Thomson, M. Kent \& R. Robertson (Eds.), Interdisciplinary approaches to disability: Looking towards the future (1st ed., pp. 109-119). Routledge.

LaBoskey, V. K. (2004). The methodology of self-study and its theoretical underpinnings. In J. J. Loughran, M. L. Hamilton, V. K. LaBoskey \& T. Russel (Eds.), International handbook of self-study of teaching and teacher education practices (pp. 817-869). Springer.

Ladson-Billings, G. (1995). Toward a theory of culturally relevant pedagogy. American Educational Research Journal, 32(3), 465-491. https://doi.org/10.3102/00028312032003465

Ladson-Billings, G. (2014). Culturally relevant pedagogy 2.0: A.k.a. the remix. Harvard Educational Review, 84(1), 74-84. https://eric.ed.gov/?id=EJ1034303

Love, B. (2019). We want to do more than survive: Abolitionist teaching and the pursuit of educational freedom. Beacon Press. 
MacNell, L., Driscoll, A., \& Hunt, A. N. (2015). What's in a name: Exposing gender bias in student ratings of teaching. Innovative Higher Education, 40(4), 291-303.

https://doi.org/10.1007/s10755-014-9313-4

Martinez, A. N., Valdez, C., \& Cariaga, S. (2016). Solidarity with the people: Organizing to disrupt teacher alienation. Equity \& Excellence in Education, 49(3), 300-313. https://doi.org/10.1080/10665684.2016.1194104

McAnulty, J., \& Cuenca, A. (2014). Embracing institutional authority: The emerging identity of a novice teacher educator. Studying Teacher Education, 10(1), 36-52. https://doi.org/10.1080/17425964.2013.862493

Mitchem, M., Buffalo, G. R., Perez, A., \& Rollins, E. R. (2020). Tales of existing and resisting as female teacher educators in neoliberal times. The New Educator, 16(1), 70-85. https://doi.org/10.1080/1547688X.2019.1681570

National Center for Education Statistics. (2012). Percentage of high school dropouts among persons 16-24 by sex and race/ethnicity. http://nces.ed.gov/programs/digest/d11/tables/dt11 116.asp

National Center for Education Statistics. (2016). Racial/ethnic enrollment in public schools. http://nces.ed.gov/programs/coe/indicator_cge.asp

National Center for Education Statistics. (2020). Characteristics of postsecondary faculty. The Condition of Education. https://nces.ed.gov/programs/coe/indicator csc.asp

Phendla, T. (2008). The paradox of luselo-lufhanga metaphors: African women defining leadership for social justice. Isea, 36(1), 22-40. https://journals.co.za/content/jeds/2011/si-1/EJC160138

Picower, B., \& Kohli, R. (Eds.). (2017). Confronting racism in teacher education: Counternarratives of critical practice. Routledge.

Pugach, M. C., Blanton, L. P., Mickelson, A. M., \& Boveda, M. (2020). Curriculum theory: The missing perspective in teacher education for inclusion. Teacher Education and Special Education, 43(1), 85-103. https://doi.org/10.1177/0888406419883665

Reid, L. (2010). The role of perceived race and gender in the evaluation of college teaching on ratemyprofessors.com. Journal of Diversity in Higher Education, 3(3), 137-152. https://doi.org/10.1037/a0019865

Saldaña, J. (2016). The coding manual for qualitative researchers (3rd ed.). Sage Publications.

Sleeter, C. E. (2012). Confronting the marginalization of culturally responsive pedagogy. Urban Education, 47(3), 562-584. https://doi.org/10.1177/0042085911431472

Smith, B. P., \& Hawkins, B. (2011). Examining student evaluations for Black college faculty: Does race matter? Journal of Negro Education, 80(2), 149-162. https://eric.ed.gov/?id=EJ942385

Taie, S., Goldring, R., \& Spiegelman, M. (2017, August). Characteristics of public elementary and secondary school teachers in the United States: Results from the 2015-2016 national teacher and principal survey. National Center for Education Statistics. https://files.eric.ed.gov/fulltext/ED575193.pdf 


\section{$\checkmark$ JCVE}

www.cultureandvalues.org

Journal of Culture and Values in Education

Volume 3 Issue 1, 2020

Kressler, B., Critical self-reflection as disruption: A Black feminist self-study

Wilson, R. (2016, November 6). A new front of activism: Cases of minority scholars denied tenure call into question the long-term plans to diversify. The Chronicle of Higher Education. https://www.chronicle.com/article/A-New-Front-of-Activism/238319 